adequate pre-MTX labs (hematology, renal and liver panel and or hepatitis serology) requested by $46 \%$ in 2016 to $90 \%$ in $2018 \quad(p<0.0001)$. When documented, MTX use was often interupted (2016 17/24; 2018 14/ $43 \mathrm{p}=0.003$ ) and mainly due to limited drug availability.

Conclusion: An educational program conducted with support from the local medical community has potential to improve management of rheumatic disease in resource limited regions without adequate rheumatology capacity. However, interventions must be maintained over time and changes in practice measured to ensure that appropriate diagnosis and safe prescribing practices continue until local rheumatology expertise and capacity is available.

Acknowledgement: Study funding by ILAR

Disclosure of Interests: CArol Hitchon Grant/research support from: Pfizer, UCB (unrelated studies), Becky Abdissa Adugna: None declared, Birhanu Demelash: None declared, Rosie Scuccimarri: None declared, Ines Colmegna: None declared, Frehiywot Kifle : None declared, Paul Caldron: None declared, Addisu Melkie: None declared, Michele Meltzer: None declared, Yewondwossen Mengistu: None declared DOI: 10.1136/annrheumdis-2019-eular.3581

\section{AB1344 'CLINICAL ASSESSMENT OF THE MUSCULOSKELETAL SYSTEM' HANDBOOK AND ACCOMPANYING VIDEOS: 15 YEARS OF USE}

Cheuk Yin $\mathrm{Li}^{1}$, Sophia Wakefield ${ }^{2}$, Donna Andrew ${ }^{3}$, David Coady ${ }^{4}$, Versus Arthritis ${ }^{1}$ Newcastle University, Newcastle upon Tyne, United Kingdom; ${ }^{2}$ Cardiff University, Cardiff, United Kingdom; ${ }^{3}$ Versus Arthritis, Chesterfield, United Kingdom; ${ }^{4}$ City Hospitals Sunderland, Sunderland, United Kingdom

Background: 15 years ago, Arthritis Research UK (ARUK) produced the 'Clinical Assessment of the Musculoskeletal (MSK) System' handbook and a set of accompanying videos; 'Regional Examination of the Musculoskeletal System'.(1) There has been an evaluation of the use of this resource showing that they are widely used among medical students and healthcare professionals. Recently, ARUK has merged with Arthritis Care to create Versus Arthritis, and previous publications are due to be rebranded.

Objectives: This project aims to review how the handbook and videos are being used 15 years on. The secondary aim is to gain insight into any changes that may need to be made going forward as Versus Arthritis seeks to revise and update the original materials.

Methods: In September 2018, a clinical group was formed to review the current handbook's content and format. The project team was invited to take part in the surveys and disseminate them within their professional networks and across every UK medical school.

Results: 78 people took part in the survey; this included 61 users (students and trainees) and 17 medical school teachers.

User Survey: 'How to access the handbook? respondents said online $(36 \%)$, via an app (31\%) or printed version $(10 \%)$. $83 \%$ of respondents said they found the handbook very useful, $100 \%$ said it was easy to understand, 95\% said it was well illustrated, and $75 \%$ said the video clips were very useful. $100 \%$ of respondents said the handbook did not contradict any previous teaching received.

When asked what would improve the handbook, the most popular response was case studies. When asked what the most useful thing was, most respondents commented on the structure and how clear and concise it was. When asked what the least useful thing was, respondents felt it lacked detail regarding the rationale behind the purpose of the examinations.

Teacher Survey: 17 medical school representatives completed the survey. $94 \%$ of respondents use the resource. Most provide their students with the online version of the handbook (64\%). $88 \%$ thought the resource was very useful for their students. $94 \%$ said the resource maps well to the current MSK curriculum. When asked what would improve the handbook the most popular response was abnormal examination findings. The least popular response was patient exercise videos and sheets.

Content Review: Several comments were made suggesting the use of more appropriate language. Recommendations were made to introduce sections on physical activity, self-management and the multidisciplinary team involvement. A suggestion was made to include the patient's 'ideas, concerns and expectations' concept.

Conclusion: The consensus is that the resource is already very good and maps well to the MSK curriculum taught by the medical schools. It would benefit from adding new contents, e.g. examination clips of patients with pathology. We would need to be wary of overcomplicating the purpose of the new resource.

It was also highlighted that the resource would benefit from a refresh of the layout, including clear headings and more up to date images and diagrams. Several comments were made around the format to include an online resource that students could use to incorporate examination videos with experts explaining the findings.

\section{REFERENCES}

[1] Arthritis Research UK. 2018. Information for Health Professionals and Stu dents. [Online] Available at: https://www.arthritisresearchuk.org/shop/products/publications/information-for-medical-professionals.aspx [Accessed 30 January 2019].

Acknowledgement: Louise Warburton, Ana Onebieni, Singh Harjinder, Pippa Watson, Mark Lilicrap, Anita Williams, Sarah-Jane Ryan, Jade Pullen, Stephanie Saltford

Disclosure of Interests: Cheuk Yin Li: None declared, Sophia Wakefield: None declared, Donna Andrew: None declared, David Coady Grant research support from: Currently, hold a grant of $£ 10,000$ from Biogen, Consultant for: Yes as part of Medical Board for Internis, Speakers bureau: Yes, multiple speaker fees for a variety of companies DOI: 10.1136/annrheumdis-2019-eular.5893

\section{AB1345 CONTEXTUAL FACTORS IMPACTING OSTEOARTHRITIS MANAGEMENT IN URBAN AND RURAL COMMUNITY- DWELLING SENIORS: AN ANALYSIS BASED ON THE INTERNATIONAL CLASSIFICATION OF FUNCTIONING DISABILITY AND HEALTH}

Joy MacDermid ${ }^{1,2}$, Karen Lee ${ }^{1}$, Amanda Ali ${ }^{1}{ }^{1}$ Western University, Faculty of Health Science, London, Canada; ${ }^{2}$ St Joseph's Health Centre, Hand and Upper Limb Centre, London, Canada

Background: Living with arthritis requires lifelong management that can be influenced by person, place and context.

Objectives: The objectives of this study were to: (1) identify contextua factors that influence $O A$ management in rural and urban-dwelling seniors and (2) examine how contextual factors identified by rural and urbandwelling seniors are explained in terms of the ICF framework

Methods: Semi-structured interviews were conducted with 20 communitydwelling seniors in Ontario, Canada.; purposivel inclding 11 seniors from an urban setting and 9 seniors from a rural setting, all over the age of 65 , and previously diagnosed with OA. Broad questions on self-management and information weeking were explored. Interview concepts related to the environmental and contextual factors component were extracted from interview transcripts and organized into subthemes. Meaningful concepts were linked by 2 raters to ICF categories according to established linking rules. Descriptive analyses were performed.

Results: A total of 891 meaningful concepts were identified; 481 from interviews with 11 urban-dwelling seniors and were linked to 54 ICF categories: 24 Environmental Factors, 21 Activities and Participation, and 9 Body Functions and 410 meaningful concepts from interviews with 9 rural-dwelling seniors: 57 ICF categories: 27 Environmental Factors, 24 Activities and Participation, and 6 Body Functions. Within Activities and Participation component, "d839 Education" was the most code for both groups. From the Body Functions component, "b1800 Experiences of Self" followed by "b1301 Motivation" were most mentioned. Environmental factors represented 203 of 481 (42.2\%) urban concepts and 253 of 410 $(61.7 \%)$ rural concepts. The concepts linked to the Activities and Participation category were similar across urban and rural groups $(17.3 \%$ and $17.1 \%$ ). Personal Factors (e.g. "adapting to life with OA", "self-sufficiency", "pain tolerance", "age") or "nc - not covered" (e.g. "feeling old", "embarrassed by OA", "being a burden") were not coded. In $12.2 \%$ urban and $20.6 \%$ rural content was labeled as Personal Factors. Chapter e5 services, systems and policies was the chapter with the highest coverage overall. Within the environmental factors "e355 Health Professionals" was the most common code for both urban and rural groups, and mentioned in almost all interviews. Participants frequently discussed physician's attitudes and misconceptions towards patients with OA.

Conclusion: The complex interaction of personal and environmental fac tors impacting $\mathrm{OA}$ management in both urban and rural communities was illustrated. Rurality influences some aspects of ths complexity, but many common themes occur.

\section{REFERENCES}

[1] Weigl M, Cieza A, Harder M, et al. Linking osteoarthritis-specific health-status measures to the international classification of functioning, disability, and health (ICF). Osteoarthr Cartil. 2003;11(7):519-523. doi S1063458403000864 [pii]. 
[2] Cieza A, Geyh S, Chatterji S, Kostanjsek N, Üstün B, Stucki G. ICF linking rules: An update based on lessons learned. J Rehabil Med. 2005;37 (4):212-218. doi:10.1080/16501970510040263.

Disclosure of Interests: None declared

DOI: 10.1136/annrheumdis-2019-eular.3524

\section{AB1346 PATIENTS‘ BELIEFS ABOUT MEDICINES PRESCRIBED FOR THEIR RHEUMATOID ARTHRITIS OR SPONDYLOARTHRITIS}

Nathalie Madeira, Candida Silva, Claudia Miguel, Dina Medeiros, Filipe Barcelos, Helena Santos, Ricardo Trinca, Alexandra Cardoso, Luís Cunha Miranda. Instituto Português de Reumatologia, Rheumatology, Lisbon, Portugal

Background: Adherence to therapies is determined by multiple factors, some of which are patient's related and include economic resources, knowledge, attitudes, beliefs, perceptions and expectations about medication.

Objectives: To assess patients' beliefs about prescribed medication for their rheumatic disease (rheumatoid arthritis (RA) or spondyloarthritis $(\mathrm{SpA})$, including psoriatic arthritis) and to determine the existence of any association between these beliefs and clinical and socio-demographic variables.

Methods: Observational cross-sectional study which included RA patients according to 1987 ACR and/or 2010 ACR/EULAR criteria and SpA patients according to 2009 ASAS classification criteria (CC) for axial SpA or to 2011 ASAS CC for peripheral SpA, on subcutaneous biological therapy, followed at our Center, able to complete questionnaires autonomously and who agreed to participate. Socio-demographic and clinical data, anxiety and depression through the Hospital Anxiety and Depression Scale (HADS) and fatigue using the Functional Assessment of Chronic IIIness Therapy - Fatigue questionnaire (FACIT-F) were collected. To assess beliefs about medication, the cross-culturally adapted Portuguese version of the Beliefs about Medicines Questionnaire (BMQ)-Specific was used, asking patients to apply it considering only the prescribed medicines for AR or SpA. The BMQ-Specific comprises two subscales: a fiveitem Necessity scale (Specific-Necessity, SN) and a six-item Concerns scale (Specific-Concerns, SC). Each item is scored on a five-point Likert scale (from $1=$ strongly disagree to $5=$ strongly agree). Statistics: descriptive, Mann-Whitney and Kruskal-Wallis tests and Spearman correlation, $\mathrm{p}<0.05$.

\begin{tabular}{lcc}
\hline & RA patients & SpA patients \\
\hline Current age - years & Median (IQR) & Median (IQR) \\
& $60,0(51,0-$ & $47,0(39,5-$ \\
Disease duration - years & $66,0)$ & $57,0)$ \\
& $14,5(12,0-$ & $13,0(8,0-$ \\
Time on treatment with the current biologic therapy - & $18,3)$ & $19,0)$ \\
months & $31,0(20,0-$ & $37,0(12,0-$ \\
PGA & $62,0)$ & $83,0)$ \\
& $32,0(6,0-$ & $29,0(14,5-$ \\
VAS pain & $55,0)$ & $51,5)$ \\
& $41,0(21.0-$ & - \\
PhGA & $60.0)$ & $12,5(5,0-$ \\
& $19,5(6,5-$ & $23,5)$ \\
Nocturnal back pain VAS & $33,8)$ & $17,0(4,5-$ \\
& - & $34,0)$ \\
Back pain VAS & & $18,0(5.5-$ \\
& - & $43,0)$ \\
VS - mm/H & $15,0(7,0-$ & $7,0(2,0-14,0)$ \\
& $30,5)$ & \\
CRP - mg/dL & $0,2(0,1-0,6)$ & $0,3(0,1-1,0)$ \\
DAS28_4V & $3,2(2,4-4,4)$ & - \\
BASDAI & - & $2,8(1,1-4,6)$ \\
ASDAS & - & $1,8(1,1-2,4)$ \\
BASMI & - & $2,7(2,1-4,0)$ \\
HAQ & $18,0(15,0-$ & $18,0(13,5-$ \\
BASFI & $22,0)$ & $22,0)$ \\
BMQ-SN & & - \\
BMQ-SC & - & $1,8(0,7-3,7)$ \\
\hline
\end{tabular}

Abstract AB1346 Table 1. Descriptive statistics of the continuous variables of the RA and SpA patients

Results: We obtained data from 84 patients, $45 \mathrm{SpA}$ (53.6\%) and 39 (46.4\%) RA patients. Table 1 presents the descriptive statistics of the continuous variables. In RA group, 92.3\% were female, $84.6 \%$ under antiTNF, $66.7 \%$ under their 1st biologic and we found an association between BMQ-SC score and HADS-anxiety $(p=0.013)$ and positive correlations between BMQ-SC score and Patient Global Assessment (PGA) $(p=0.031)$, VAS pain $(p=0.004)$, Physician's Global Assessment (PhGA) $(p=0.004)$, DAS28 $(p=0.007)$, and HAQ ( $p<0.001)$. In SpA group, 62.2\% were female, $86.7 \%$ under anti-TNF, $77.8 \%$ under their 1st biologic and BMQ-SN score was positively correlated with VAS nocturnal back pain $(p=0.047)$, PhGA $(p=0.045)$ and BASFI $(p=0.003)$.

Conclusion: In RA patients, those with higher disability and a clinically more active disease presented higher levels of concern regarding the medication. In SpA, patients with a more aggressive disease, with nocturnal pain and worse function have a stronger conviction of the necessity and efficacy of the medication.

\section{REFERENCES}

[1] Salgado T, Marques A, Geraldes L, Benrimoj S. Horne R. Fernandes-Llimos F. Cross-cultural adaptation of the Beliefs about Medicines Questionnaire into Portuguese. Sao Paulo Med J. 2013; 131(2):88-94. doi:10.1590/ S1516-31802013000100018.

Disclosure of Interests: Nathalie Madeira: None declared, Candida Silva: None declared, Claudia Miguel: None declared, Dina Medeiros: None declared, Filipe Barcelos Consultant for: Pfizer; Ely-Lilly, Speakers bureau: Novartis, Helena Santos: None declared, Ricardo Trinca: None declared, Alexandra Cardoso: None declared, Luís Cunha Miranda: None declared DOI: 10.1136/annrheumdis-2019-eular.3502

\section{AB1347 ASSESSMENT OF PATIENTS‘ KNOWLEDGE ABOUT BIOLOGIC THERAPY AS A SELF-COMPLETION QUESTIONNAIRE. IS IT A GOOD WAY TO DO IT?}

Nathalie Madeira, Candida Silva, Claudia Miguel, Dina Medeiros, Filipe Barcelos, Helena Santos, Ricardo Trinca, Alexandra Cardoso, Luís Cunha Miranda. Instituto Português de Reumatologia, Rheumatology, Lisbon, Portugal

Background: Lack of knowledge from a patient in his therapy may lead to a misuse process, increasing the probability of failure to achieve the therapeutic goal.

Objectives: To evaluate if the assessment of the RA and SpA patients' knowledge in their biologic therapy could be done as a self-completion questionnaire.

Methods: Observational cross-sectional study which included patients with RA according to 1987 ACR and/or 2010 ACR/EULAR criteria or SpA according to 2009 ASAS classification criteria (CC) for axial SpA or to 2011 ASAS CC for peripheral SpA (including patients with psoriatic arthritis), on subcutaneous biological therapy who agreed to participate. Patients' knowledge about their biologic therapy was assessed using the "Conhecimento do doente sobre os seus medicamentos" (CPM-PT-PT), meaning "Patient's knowledge about his medicines", intercultural adaptation for the Portuguese version of the original Spanish questionnaire, CPMES-ES. This questionnaire was created to be used as an interview, but we decided to give it to patients and ask them to complete it autonomously, reading the questions and writing their answers, considering only their biologic therapy. It consists of 11 questions, each with a score based on patient's answer: incorrect $=-1$, the patient doesn't know $=0$, incomplete $=1$ and correct $=2$. The final score is calculated using the mathematical formula described by the authors, ranging from 0 (doesn't know the medicine) to 2 points (optimal knowledge). Statistics: descriptive, Mann-Whitney and Kruskal-Wallis tests and Spearman correlation, $p$ $<0.05$.

Results: We included 84 patients, 45 of which with SpA $(53.6 \%)$ and 39 (46.4\%) with RA. In the RA group, $92.3 \%$ were female, $84.6 \%$ were under anti-TNF $\alpha, 66.7 \%$ were under their 1st biologic, the median age was $60.0(51.0-66.0)$ years and the median time in treatment with current biologic was $31.0(20.0-62.0)$ months. In the SpA group, 62.2\% were female, $86.7 \%$ were under anti-TNF, $77.8 \%$ were under their 1 st biologic, median age was $47.0(39.5-57.0)$ years and median time in treatment with current biologic was 37.0 (12.0-83.0) months. Fifteen incomplete questionnaires were excluded. Sixty patients $(87.0 \%$ of the 69 valid questionnaires) didn't meet the minimum criteria necessary to ensure correct use of medication (correct answer to the first 5 questions), thus obtaining a CPM score of 0 . The mean CPM score was $0.2 \pm 0.5$, the median 0 (0), the minimum 0 and the maximum 1,7. There were no differences in CPM according to age, time in treatment with the current biologic, disease duration, $\mathrm{n}^{\circ}$ of previous biologics, gender, educational level, diagnosis, current biologic and $\mathrm{n}^{\circ}$ of other concomitant drugs. Table 1 